\title{
Post-Stroke Depression and Its Effect on Functional Outcomes during Inpatient Rehabilitation
}

\author{
Gurumayum Sonachand Sharma ${ }^{1}$ Anupam Gupta ${ }^{1}$ Meeka Khanna ${ }^{1}$ Naveen Bangarpet Prakash ${ }^{1}$ \\ ${ }^{1}$ Department of Neurological Rehabilitation, National Institute of \\ Mental Health and Neurosciences, Bengaluru, Karnataka, India

\begin{abstract}
Address for correspondence Anupam Gupta, MBBS, MD, Department of Neurological Rehabilitation, National Institute of Mental Health and Neurosciences, Bengaluru 560029, Karnataka, India (e-mail: drgupta159@yahoo.com).
\end{abstract}

\begin{abstract}
Keywords

- stroke

- post-stroke depression

- inpatient rehabilitation

- functional outcomes measures

Objective The aim of the study is to observe the effect of post-stroke depression on functional outcomes during inpatient rehabilitation.

Materials and Methods The design involved is prospective observational study. The location involved is Neurological Rehabilitation unit in a tertiary care university hospital. The study period ranges from October 2019 to April 2020. The participants involved are the patients with first ever stroke, male and female with age $\geq 18$ years and duration less than 1 year. All participants were assessed at admission and after 14 sessions of inpatient rehabilitation by depression subscale of Hospital Anxiety and Depression Scale (HADS-D) and Hamilton Depression Rating Scale (HDRS). The stroke outcomes measures used were: Barthel Index (BI), Scandinavian Stroke Scale (SSS), and Modified Rankin Scale (MRS).

Results There are a total of 30 participants ( 18 males) with median stroke duration of 90 days. The median age of the patients was 58 years. Sixteen patients had ischemic and 14 had hemorrhagic stroke. Out of these, 57\% $(n=17)$ had symptoms of depression (HADS-D >7). Participants in both groups (with and without depression) showed improvement in all the functional outcome measures (BI, SSS, MRS) at the time of discharge as compared with admission scores. The changes in the outcome measures were statistically significant within groups $(p<0.05)$ but not significant between the groups $(p>0.05)$.

Conclusion The post-stroke depression is common among stroke survivors of less than 1 year duration. There was no significant difference in the functional outcomes between stroke patients with depression and those without depression with inpatient rehabilitation program.
\end{abstract}

published online June 25, 2021
DOI https://doi.org/

$10.1055 / \mathrm{s}-0041-1731958$ ISSN 0976-3147 (c) 2021. Association for Helping Neurosurgical Sick People.

This is an open access article published by Thieme under the terms of the Creative Commons Attribution-NonDerivative-NonCommercial-License, permitting copying and reproduction so long as the original work is given appropriate credit. Contents may not be used for commercial purposes, or adapted, remixed, transformed or built upon. (https://creativecommons.org/licenses/by-nc-nd/4.0/). Thieme Medical and Scientific Publishers Private Ltd. A-12, Second Floor, Sector -2, NOIDA -201301, India 


\section{Introduction}

Post-stroke sequelae are one of the major causes of adult disability worldwide, with nearly $60 \%$ of the survivors experiencing long-term functional disabilities. ${ }^{1,2}$ They have increased incidences of neuropsychiatric disorders, such as depression, generalized anxiety, post-traumatic stress disorder, psychotic states, apathy, and obsessive disorders, etc. $^{3}$ Among these, depression is reported to be present in 20 to $65 \%$ of patients with highest incidence during the initial 3 to 6 months following stroke. ${ }^{4-6}$ By definition, post-stroke depression (PSD) does not exist before the stroke and occurs in chronological context of a stroke. PSD is known to be associated with poor outcomes of both inpatient and outpatient rehabilitation, increased risk of recurrent stroke, and mortality. Still, it is under diagnosed and frequently overlooked. ${ }^{7-12}$ The existing literature on PSD is predominantly focused on the prevalence, risk factors, relation with stroke characteristics, and effect on the quality of life. ${ }^{13-16}$ There are very few prospective studies on the effect of PSD on the functional outcomes during inpatient rehabilitation, so this study was conducted to look into this issue at some length.

\section{Materials and Methods}

This observational prospective study was performed in neurorehabilitation unit of a tertiary hospital between October 2019 and April 2020. Study population included stroke patients undergoing inpatient rehabilitation. Inclusion criteria were: first ever arterial stroke with less than 1 year duration and age $\geq 18$ years. Both ischemic and hemorrhagic strokes were included. Exclusion criteria were: patients unable to or not willing to give consent, recurrent stroke, severe cognitive impairment (Montreal Cognitive Assessment scores $\leq 25$ ), pre-existing psychiatric illness, having communication disorder, i.e., global aphasia, hearing impairment, and severe comorbid conditions like recent myocardial infarction, unstable angina, contracture of joints, etc. Approval from the Institute's Ethics Committee was obtained before commencement of the study.

Informed consent was obtained from the patients followed by detailed clinical and neurological examinations. The demographic details, clinical complaints, and examination findings were recorded. Patients were assessed for both depression and functional outcomes on day 1 of admission and after the completion of 14 sessions of inpatient rehabilitation. They received daily neurological rehabilitation program which included physiotherapy, occupational therapy, clinical psychotherapy, and psychosocial counseling. Physiotherapy program included exercises for range of motion, stretching, and strengthening of affected limb, along with balance and gait training with assistive device (if required). The occupational therapy program comprised of training to perform activities of daily living (ADL), functional abilities training, fine and gross motor activities. The clinical psychologist performed psychotherapy which was focused mainly on cognitive assessment and retraining in the affected domains. They also addressed the issue of neuropathic pain in patients who were not responding to pharmacotherapy alone. The psychosocial counseling included awareness and counseling about the illness, emotional and financial support and the counseling was conducted by a psychiatric social worker.

\section{Assessment and Outcome Measures}

Patients were screened for depression, using depression subscale of Hospital Anxiety Depression Scale (HADS-D). ${ }^{17}$ It consists of 7-item questionnaire on depression and responses range from 0 to 3 with final scores ranging from 0 to 21. A score of more than 7 in HADS-D was considered as depression. The patients were divided into two groups, i.e., those with no depression and with depression. The Hamilton Depression Rating Scale (HDRS) was used as adjunct to the HADS-D score. ${ }^{18}$ The HDRS consists of 17 -items questionnaire depending on the symptoms of depression with scores ranging from 0 to 52 .

The functional ability of patients was assessed using Barthel Index (BI) scores. ${ }^{19}$ It is a 10-item scale, which assesses a person's ability in performing ADL including feeding, grooming, bathing, dressing (both upper and lower half), personal toilet, bladder and bowel care, transfers, stair negotiation abilities, and mobility. It is a 100-point scale, with better functional independence denoted by higher scores.

Post-stroke impairment was measured using Scandinavian Stroke Scale (SSS). It consists of nine items generating a minimum score of 2 (worst neurological compromise) and a maximum score of 58 (without neurological compromise). There are nine items consisting of consciousness, orientation, eye movement, speech, facial palsy, arm motor power, hand motor power, leg motor power, and gait. ${ }^{20}$

Modified Rankin Scale (MRS) was used to stratify disability in the patients following stroke. ${ }^{21}$ The scores range from 0 to 6 , measuring from perfect health without symptoms (score 0 ) to death (score 6).

\section{Statistical Analysis}

The data collected was analyzed using $\mathrm{R}$ software of version 3.4.4 and basic descriptive statistics was computed. The correlation graph was plotted using SOFA statistics (www.sofastatistics.com). Statistical significance was assessed by appropriate tests like Chi-square test, Wilcoxon rank sum test, and Mann-Whitney test. The Spearman's test was used for correlation. The statistical significance was defined as $p<0.05$.

\section{Results}

A total of 388 stroke patients were screened in the outpatient services of the department. Out of these, 31 participants fulfilled the inclusion criteria. One participant did not complete the study. Following screening with HADS-D score, 17 participants were found to have depression (HADS-D $\geq 8$ ) while 13 did not have depression ( - Fig. 1).

The demographic and clinical profile of the patients is depicted in - Table 1. The baseline characteristics were not significant amongst the groups except in age. The median age 


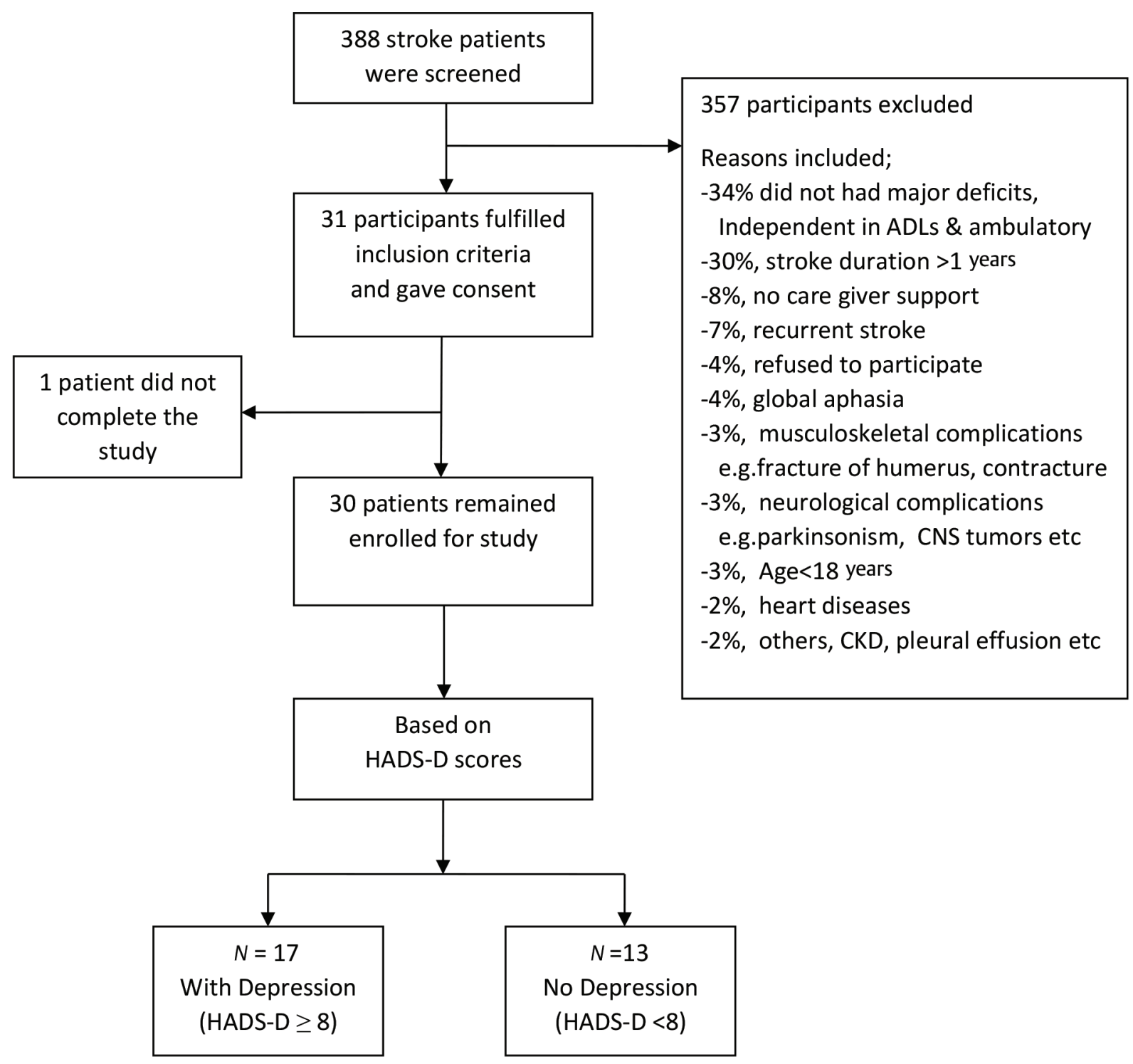

Fig. 1 Flowchart showing details of the stroke patients screened for the study.

was 58 years in group with depression and 37 years in those without depression. Majority of the patients were men and left-sided hemiplegia was more common in both the groups. Median duration of stroke was 90 days (both groups).

Patients without depression showed significant improvement in functional recovery with $\mathrm{BI}(p=0.001)$ and SSS, $(p=$ 0.001 ) but it was not significant for MRS $(p=0.062)$. Similarly, patients with depression also showed improvement in the outcome measures at the time of discharge which was significant for BI ( $p=0.001)$, SSS ( $p=0.003)$ but not significant for MRS ( $p=0.07)$. So, in both the groups, a significant improvement was observed in outcome measures at the time of discharge as compared with admission (-Table 2 ).

However, there was no significant difference using same outcome measures when between groups comparison was made. The median difference of scores (discharge-admission) for BI and SSS were higher for patients without depression when compared with those with depression. But this was statistically not significant ( $p=0.13$ for BI, $p=0.45$ for SSS, and $p=0.49$ for MRS) ( - Table 3 ).

The Spearman correlation test showed there is significant correlation between HADS-D with BI and SSS i.e., $r=0.62, p=$ 0.001 and $r=0.65, p=0.004$, respectively. No significant correlation was observed for HADS-D with MRS, i.e., $r=0.22$ and $p=0.38$ (-Fig. 2). The similar correlation was also found between HDRS and outcome measures (- Table 4 ).

In subgroup analysis of patients with depression $(n=17)$ at discharge, 10 of these recovered from depression (HADS-D $<8)$ while seven individuals continued to be depressed (HADS-D $\geq 8$ ). At discharge, the outcome scores (BI, SSS, and MRS) between the two subgroups were statistically significant (-Table 5). 
Table 1 Baseline demographic and clinical characteristics of the patients $(n=30)$ at admission

\begin{tabular}{|c|c|c|c|c|}
\hline S no. & Variables & $\begin{array}{l}\text { Group with depression } \\
(N=17)\end{array}$ & $\begin{array}{l}\text { Group without } \\
\text { depression }(N=13)\end{array}$ & $p$-Value \\
\hline 1 & $\begin{array}{l}\text { Age (in years) } \\
\text { Median (IQR) }\end{array}$ & $58(61,49)$ & $37(52,34)$ & $0.01^{\mathrm{a}}$ \\
\hline \multirow[t]{3}{*}{2} & Gender & & & \multirow[t]{3}{*}{$0.50^{\mathrm{b}}$} \\
\hline & Male & $11(65 \%)$ & 7 (54\%) & \\
\hline & Female & $6(35 \%)$ & $6(46 \%)$ & \\
\hline \multirow[t]{2}{*}{3} & Duration of stroke (in days) & & & \multirow[t]{2}{*}{$0.27^{\mathrm{a}}$} \\
\hline & Median (IQR) & $90(210,30)$ & $90(120,30)$ & \\
\hline \multirow[t]{3}{*}{4} & Type of stroke & & & \multirow[t]{3}{*}{$0.43^{b}$} \\
\hline & Hemorrhagic & $9(52 \%)$ & $5(38 \%)$ & \\
\hline & Ischemic & $8(48 \%)$ & $8(62 \%)$ & \\
\hline \multirow[t]{3}{*}{5} & Side of hemiplegia & & & \multirow[t]{3}{*}{$0.55^{b}$} \\
\hline & Right & $6(35 \%)$ & $6(46 \%)$ & \\
\hline & Left & $11(65 \%)$ & 7 (54\%) & \\
\hline \multirow[t]{4}{*}{6} & Aphasia & & & \multirow[t]{4}{*}{$0.012^{\mathrm{b}}$} \\
\hline & $1=$ Motor & $0(0 \%)$ & $5(38 \%)$ & \\
\hline & $2=$ Normal (No aphasia) & $5(30 \%)$ & $4(31 \%)$ & \\
\hline & $3=$ Others & $12(70 \%)$ & $4(31 \%)$ & \\
\hline \multirow[t]{4}{*}{7} & Sensations & & & \multirow[t]{4}{*}{$0.134^{b}$} \\
\hline & 1 = Absent & $6(35 \%)$ & $1(8 \%)$ & \\
\hline & 2 = Impaired & $5(30 \%)$ & $8(61 \%)$ & \\
\hline & $3=$ Normal & $6(35 \%)$ & $4(31 \%)$ & \\
\hline \multirow[t]{3}{*}{8} & Shoulder pain & & & \multirow[t]{3}{*}{$0.31^{\mathrm{b}}$} \\
\hline & Present & $13(76 \%)$ & $8(61 \%)$ & \\
\hline & Absent & $4(24 \%)$ & $5(49 \%)$ & \\
\hline \multirow[t]{2}{*}{9} & Barthel Index scores & & & \multirow[t]{2}{*}{$0.20^{\mathrm{a}}$} \\
\hline & Median (IQR) & $48(50,45)$ & $55(60,45)$ & \\
\hline 10 & $\begin{array}{l}\text { Scandinavian stroke scale scores } \\
\text { Median (IQR) }\end{array}$ & $33(37,28)$ & $38(42,34)$ & $0.05^{\mathrm{a}}$ \\
\hline \multirow[t]{2}{*}{11} & Modified Rankin scale scores & & & \multirow[t]{2}{*}{$0.30^{\mathrm{a}}$} \\
\hline & Median (IQR) & $4(4,4)$ & $4(4,3)$ & \\
\hline
\end{tabular}

Abbreviation: IQR, interquartile range.

aMann-Whitney $\mathrm{U}$ test (Wilcoxon rank sum test).

${ }^{\mathrm{b} C h i-s q u a r e ~ t e s t . ~}$

Table 2 Outcome measures within the groups' comparison at discharge

\begin{tabular}{|c|c|c|c|c|c|c|c|c|c|c|}
\hline \multirow[t]{3}{*}{ Outcomes } & \multicolumn{5}{|c|}{ Without depression $n=13$} & \multicolumn{5}{|c|}{ With depression $n=17$} \\
\hline & \multicolumn{2}{|c|}{ Admission } & \multicolumn{2}{|c|}{ Discharge } & \multirow[t]{2}{*}{$p$-Value } & \multicolumn{2}{|c|}{ Admission } & \multicolumn{2}{|c|}{ Discharge } & \multirow[t]{2}{*}{$p$-Value } \\
\hline & Median & Q3-Q1 & Median & Q3-Q1 & & Median & Q3-Q1 & Median & Q3-Q1 & \\
\hline $\mathrm{BI}$ & 55 & $60-45$ & 70 & $85-55$ & $<0.001$ & 48 & $50-45$ & 65 & $75-45$ & $<0.001$ \\
\hline SSS & 38 & $42-34$ & 43 & $49-37$ & $<0.001$ & 33 & $37-28$ & 40 & $41-30$ & 0.003 \\
\hline MRS & 4 & $4-3$ & 3 & $4-3$ & 0.062 & 4 & $4-4$ & 4 & $4-3$ & 0.007 \\
\hline
\end{tabular}

Abbreviations: BI, Barthel Index; IQR, inter quartile range; MRS, Modified Rankin Scale; SSS, Scandinavian Stroke Scale. 
Table 3 Difference of scores (discharge admission)

\begin{tabular}{|l|l|l|l|l|l|l|}
\hline \multirow{2}{*}{ S no. } & \multirow{2}{*}{ Outcomes } & With depression $\boldsymbol{n}=17$ & \multicolumn{3}{l|}{ Without depression $\boldsymbol{n}=13$} & $\boldsymbol{p}$-Value \\
\cline { 3 - 7 } & & Median & $\mathbf{( Q 3 - Q 1 )}$ & Median & (Q3-Q1) & \\
\hline 1 & Barthel Index Scores & 10 & $20-5$ & 15 & $25-15$ & 0.13 \\
\hline 2 & Scandinavian Stroke Scale Scores & 3 & $7-0$ & 4 & $8-2$ & 0.45 \\
\hline 3 & Modified Rankin Scale Scores & 0 & $0,-1$ & 0 & $0,-1$ & 0.49 \\
\hline
\end{tabular}

(A)

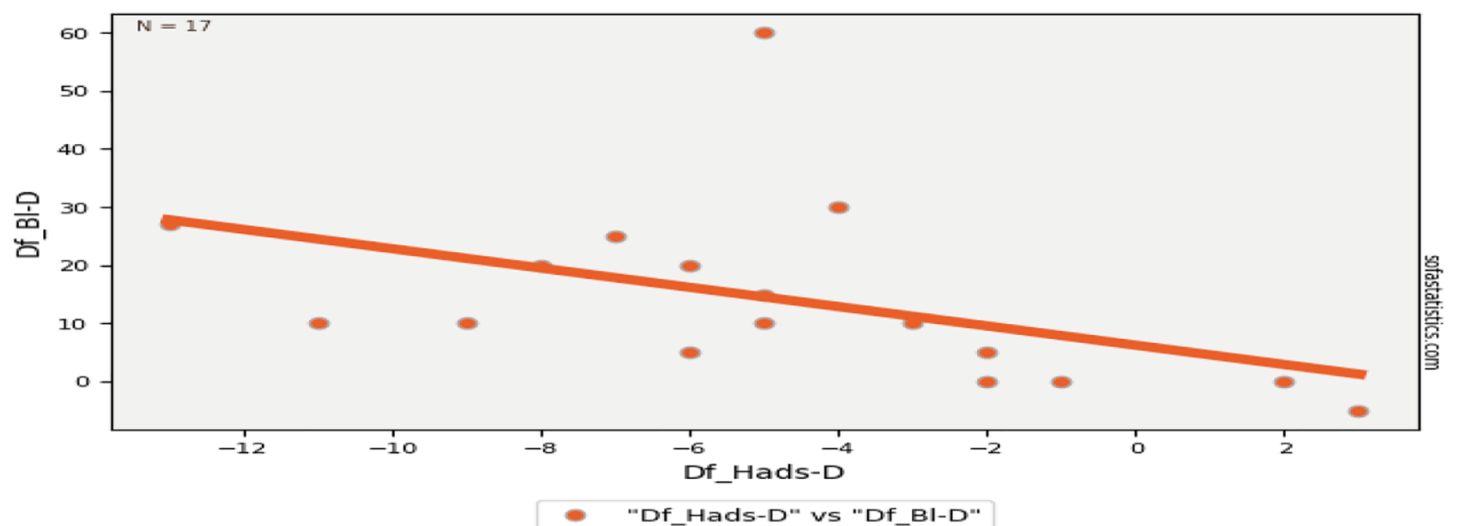

(B)

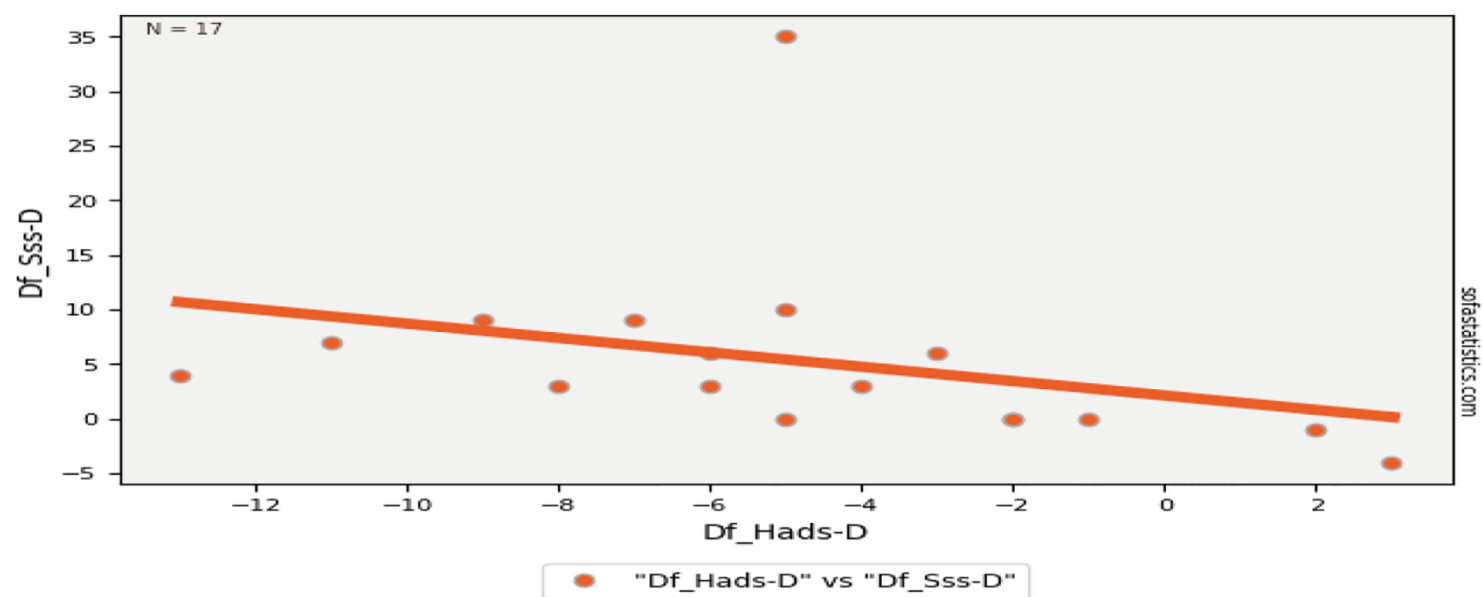

Fig. 2 Relationship between (A) HADS-D and Barthel Index (BI), (B) HADS-D and Scandinavian Stroke Scale (SSS) with regard to the difference in score between admission and discharge (Diff). HADS-D, depression subscale of Hospital Anxiety and Depression Scale; HDRS, Hamilton Depression Rating Scale.

Table 4 Spearman's Rank correlation calculated with difference of outcome scores of admission and discharge in patients with depression $(n=17)$

\begin{tabular}{|l|l|l|l|l|}
\hline \multicolumn{2}{|c|}{} & Dif. of scores BI & Dif. of scores MRS & Dif. of scores SSS \\
\hline \multirow{2}{*}{ Dif. of scores HADS-D } & $r$ & 0.62 & 0.22 & 0.65 \\
\cline { 2 - 5 } & $p$ & $<0.001$ & 0.38 & 0.004 \\
\hline \multirow{2}{*}{ Dif. of scores HDRS } & $r$ & 0.73 & 0.4 & 0.67 \\
\cline { 2 - 5 } & $p$ & $<0.001$ & 0.1 & 0.002 \\
\hline
\end{tabular}

Abbreviations: Dif, difference of scores between admission and discharge; HADS-D, depression subscale of Hospital Anxiety and Depression Scale; HDRS, Hamilton Depression Rating Scale; MRS, Modified Rankin Scale; SSS, Scandinavian Stroke Scale. 
Table 5 Subgroup data analysis among depressed patients $(n=17)$ at discharge

\begin{tabular}{|c|c|c|c|c|c|c|}
\hline \multirow[t]{2}{*}{ S. no. } & \multirow[t]{2}{*}{ Outcomes } & \multicolumn{2}{|c|}{$\begin{array}{l}\text { Still in depression } \\
(\text { HADS-D } \geq 8, n=7)\end{array}$} & \multicolumn{2}{|c|}{$\begin{array}{l}\text { Without depression } \\
(\text { HADS-D< } 8, n=10)\end{array}$} & \multirow[t]{2}{*}{$p$-Value } \\
\hline & & Median & (Q3-Q1) & Median & (Q3-Q1) & \\
\hline 1 & Barthel Index Scores & 0 & $10-0$ & 20 & $26.5-11$ & 0.004 \\
\hline 2 & $\begin{array}{l}\text { Scandinavian Stroke } \\
\text { Scale Scores }\end{array}$ & 0 & $3-(0.5)$ & 5 & $8.5-3$ & 0.04 \\
\hline 3 & $\begin{array}{l}\text { Modified Rankin Scale } \\
\text { Scores }\end{array}$ & 0 & $0-0$ & 1 & $1-(1)$ & 0.002 \\
\hline
\end{tabular}

Abbreviations: HADS-D, depression subscale of Hospital Anxiety and Depression Scale; HDRS, Hamilton Depression Rating Scale.

\section{Discussion}

The present study targeted stroke survivors of less than 1 year duration with PSD and functional outcomes following arterial stroke. PSD was more common in elderly males with left hemiplegia who were also having shoulder pain. Berg et al observed in their study that the older males were more depressed following strokes. ${ }^{22}$ The reason behind might be: males were more concerned about working disability and had poor coping ability with the stroke sequelae as compare with females. ${ }^{23}$ Males are breadwinners of the family in our country and working elderly men may be concerned about how they will fulfill the roles and responsibilities following stroke which could be one of the reasons they were more depressed following stroke.

The prevalence of PSD in our study was $57 \%$ which is similar to an earlier study by Farner et al, who reported prevalence rate of PSD to be $56 \% .{ }^{24}$ Another study by Srivastava et al reported lower prevalence of PSD (35.3\%). ${ }^{25}$ The reason for higher prevalence in our study may be due to smaller sample size and unequal age distribution as well.

In the current study, the functional outcomes were significantly improved in both the groups (with and without depression). However, between the group difference was not statistically significant. This implies that the rehabilitation program resulted in effective improvement of functioning in patients with stroke irrespective of status of depression. Žikić et al observed that the functional outcomes (measured by BI) significantly improved in nondepressed as compare with depressed patients. ${ }^{14}$ The findings of our study may be due to the good family care and support, and comprehensive rehabilitation program which resulted in improvement of functional status in patients with PSD. Psychosocial counseling was done in both groups; however, it is likely that patients with depression were receptive to counseling sessions and were able to overcome the reactive depression following stroke and showed good functional recovery.

The present study also found that there was negative correlation between the change of scores in depression (HADS-D and HDRS) and change in functional outcome scores (BI, SSS) from admission to discharge. It has been reported by Ahn et al that depression scores showed significantly negative association with BI and positive association with MRS. ${ }^{15}$
A positive correlation was observed between depression and MRS in the present study but was found to be statistically insignificant. Žikić et al reported similar findings in their study with insignificant correlation between depression and functional abilities (using BI Score). ${ }^{14}$

Žikić et al in their study also observed that $26 \%$ of the patients initially diagnosed with depression experienced statistically significant recovery by the end of the study..$^{14}$ In our study, 59\% ( $n=10)$ patients in the depression group, recovered from it at the time of discharge (HADS-D $<8$ ) while in the remaining it persisted at the time of discharge (HADS-D $\geq 8$ ) which was statistically significant. In subgroup analysis, we observed that patients who recovered from depression had significantly better functional outcome scores as compared with those with persistent depression. However, this is a subgroup analysis with a very small number of patients and will require assessment with larger sample size to draw generalized conclusions.

In this study, nine patients having severe depression received oral antidepressants (selective serotonin reuptake inhibitors [SSRIs]). Hackett et $\mathrm{al}^{26}$ in their systemic review observed that the duration of SSRI treatment for the management of PSD ranged from several weeks to 12 months. In our study we assessed patients including those on oral antidepressants after 14 sessions of treatment; this short duration of assessment might not be enough time for the pharmacotherapy especially SSRIs to act as per their potential.

There are some limitations of this study like; (1) small sample size; (2) assessment of depression by self-reported questionnaires, and (3) exclusion of patients with a longer post-stroke duration, recurrent stroke, and global aphasia. Therefore, the study population is not representative of general stroke patients.

\section{Conclusion}

PSD is common among stroke survivor of less than 1 year duration. Functional outcomes in stroke survivors with and without PSD improve with comprehensive inpatient rehabilitation. Further research with larger sample size and more homogeneous cohort is required to observe the effect of PSD on functionality and disability. 


\section{Funding}

None.

\section{Conflict of Interest}

None declared.

\section{References}

1 Parker VM, Wade DT, Langton Hewer R. Loss of arm function after stroke: measurement, frequency, and recovery. Int Rehabil Med 1986;8(2):69-73

2 Lai SM, Studenski S, Duncan PW, Perera S. Persisting consequences of stroke measured by the Stroke Impact Scale. Stroke 2002;33(7):1840-1844

3 Angelelli P, Paolucci S, Bivona U, et al. Development of neuropsychiatric symptoms in poststroke patients: a cross-sectional study. Acta Psychiatr Scand 2004;110(1):55-63

4 Primeau F. Post-stroke depression: a critical review of the literature. Can J Psychiatry 1988;33(8):757-765

5 Hackett ML, Yapa C, Parag V, Anderson CS. Frequency of depression after stroke: a systematic review of observational studies. Stroke 2005;36(6):1330-1340

6 Robinson RG, Starkstein SE. Current research in affective disorders following stroke. J Neuropsychiatry Clin Neurosci 1990;2(1):1-14

7 Carod-Artal FJ. Depresión postictus (I). Epidemiología, criterios diagnósticos y factores de riesgo. Rev Neurol 2006;42(3): 169-175

8 Dafer RM, Rao M, Shareef A, Sharma A. Poststroke depression. Top Stroke Rehabil 2008;15(1):13-21

9 Sturm JW, Donnan GA, Dewey HM, et al. Quality of life after stroke: the North East Melbourne Stroke Incidence Study (NEMESIS) Stroke 2004;35(10):2340-2345

10 Morris PL, Robinson RG, Samuels J. Depression, introversion and mortality following stroke. Aust N Z J Psychiatry 1993; 27(3):443-449

11 Morris PL, Robinson RG, Andrzejewski P, Samuels J, Price TR. Association of depression with 10-year poststroke mortality. Am J Psychiatry 1993;150(1):124-129

12 Schubert DSP, Taylor C, Lee S, Mentari A, Tamaklo W. Detection of depression in the stroke patient. Psychosomatics 1992;33(3): 290-294

13 Visser MM, Aben L, Heijenbrok-Kal MH, Busschbach JJ, Ribbers GM. The relative effect of coping strategy and depression on health-related quality of life in patients in the chronic phase after stroke. J Rehabil Med 2014;46(6):514-519

14 Žikić TR, Divjak I, Jovićević M, et al. The effect of post stroke depression on functional outcome and quality of life. Acta Clin Croat 2014;53(3):294-301

15 Ahn DH, Lee YJ, Jeong JH, Kim YR, Park JB. The effect of poststroke depression on rehabilitation outcome and the impact of caregiver type as a factor of post-stroke depression. Ann Rehabil Med 2015;39(1):74-80

16 Shi YZ, Xiang YT, Yang Y, et al. Depression after minor stroke: the association with disability and quality of life-a 1-year follow-up study. Int J Geriatr Psychiatry 2016;31(4):421-427

17 Zigmond AS, Snaith RP. The hospital anxiety and depression scale. Acta Psychiatr Scand 1983;67(6):361-370

18 Zimmerman M, Martinez JH, Young D, Chelminski I, Dalrymple K. Severity classification on the Hamilton Depression Rating Scale. J Affect Disord 2013;150(2):384-388

19 Mahoney FI, Barthel DW. Functional evaluation: the Barthel index. Md State Med J 1965;14:61-65

20 Scandinavian Stroke Study Group. Multicenter trial of hemodilution in ischemic stroke-background and study protocol. Stroke 1985;16(5):885-890

21 Wilson JT, Hareendran A, Grant M, et al. Improving the assessment of outcomes in stroke: use of a structured interview to assign grades on the modified Rankin Scale. Stroke 2002;33(9):2243-2246

22 Berg A, Palomäki H, Lehtihalmes M, Lönnqvist J, Kaste M. Poststroke depression in acute phase after stroke. Cerebrovasc Dis 2001;12(1):14-20

23 Berg A, Palomäki H, Lehtihalmes M, Lönnqvist J, Kaste M. Poststroke depression: an 18-month follow-up. Stroke 2003; 34(1):138-143

24 Farner L, Wagle J, Engedal K, Flekkøy KM, Wyller TB, Fure B. Depressive symptoms in stroke patients: a 13 month follow-up study of patients referred to a rehabilitation unit. J Affect Disord 2010;127(1-3):211-218

25 Srivastava A, Taly AB, Gupta A, Murali T. Post-stroke depression: prevalence and relationship with disability in chronic stroke survivors. Ann Indian Acad Neurol 2010;13(2):123-127

26 Hackett ML, Anderson CS, House AO. Management of depression after stroke: a systematic review of pharmacological therapies. Stroke 2005;36(5):1098-1103 